\title{
RENEDI: Results of the first observational and prospective registry of transvenous lead extraction in Argentina. Inter-societary Working Group.
}

\author{
Javier Ferrari Ayarragaray ${ }^{1}$, Ricardo Speranza ${ }^{2}$, Hector Mazzetti $^{3}$, Alejandro Girela ${ }^{4}$, \\ Claudio De Zuloaga ${ }^{2}$, and Belen Nigro ${ }^{5}$ \\ ${ }^{1}$ Sanatorio de La Trinidad Mitre \\ ${ }^{2}$ Hospital Nacional Profesor Alejandro Posadas \\ ${ }^{3}$ Hospital General de Agudos Juan A Fernandez \\ ${ }^{4}$ Instituto Cardiovascular del Sur \\ ${ }^{5}$ Argentinian College of Cardiovascular Surgeons
}

July 8, 2021

\begin{abstract}
Background and aim: RENEDI ("Registro Nacional de Extracción de Dispositivos") is the first registry on Transvenous Lead Extraction (TLE) designed in Argentina with the objective of providing data on lead extraction real-world practice. Methods: An online database platform was designed. Data referred to patients, leads and extraction procedures were compiled and reviewed by a Committee. Results: A total of 621 leads were extracted from 325 patients (average age of 59 years; $71 \%$ male). The targeted leads included 374 pacemaker leads (61\%), 176 implantable cardioverter-defibrillator leads (28\%) and 71 cardiac resynchronization therapy devices (11\%). Two hundred and thirty-three (38\%) atrial, 367 (59\%) ventricular and 21 (3\%) coronary sinus leads placement. The average lead dwell time was 105. 9 months. The commonest indication for removal was infection (68\%-Local $71 \%$ ). Cardiovascular surgeons were usually the primary operator (81\%). The presence of cardiovascular stand-by was reported in $72 \%$ of cases. Percutaneous approach (98\%) was predominant. A total of 158 (25\%) leads with a median dwell time of 33.3 months were extracted using simple traction. Overall complication rate was $4 \%$. Only one major complication and no deaths were informed. Minor complications occurred in $3.6 \%$ of procedures. Complete procedural success was $96.2 \%$. Incomplete extraction was obtained in 23 leads. No permanent disabling complications or procedure-related deaths were reported. Conclusions: Current Argentinian practice has demonstrated that TLE is a safe and effective procedure associated with a low incidence of complications and high success rate when it is performed in well-trained hands.
\end{abstract}

\section{INTRODUCTION}

Over the past years, the number of leads extractions (LE) has increased in direct relationship to the increased numbers of cardiovascular implantable electronic devices (CIEDs) implants. This could be related not only to population growth and increasing life expectancy but also to wider indications, development of new technologies and better access to healthcare. ${ }^{1}$

RENEDI ("Registro Nacional de Extracción de Dispositivos") is the first Inter-societary, observational and prospective registry on transvenous lead extraction (TLE) in Argentina designed with the objective of providing data on lead extraction real-world practice in our country.

\section{METHODS}


A prospective, multi center and observational national cohort study for patients undergoing transvenous lead extraction (TLE) was performed.

An online platform active since January 2018 to December 2019 was designed to support the first national registry. It was launched by Argentinian College of Cardiovascular Surgeons (CACCV) in co-operation with Argentinian College of Cardiac Electrophysiology (SADEC), Argentinian College of Cardiology (SAC), and Argentinian Federation of Cardiology (FAC). The Executive Committee composed of members from these societies provided the study design. No specific protocol or recommendations regarding techniques were made for TLE procedures. Database quality and integrity were also performed by this Executive Committee.

Data were obtained for 325 patients and 621 targeted leads. The following information was provided by qualified reporters using a standard web-based electronic format: demographics data (age, gender), type of device (pacemaker, cardioverter-defibrillator implantation (CDI) or cardiac resynchronization therapy Device (CRTD), lead location (atrium, ventricle or coronary sinus), average implant time, indication for removal (in case of infection, bacteriologic organism identified), re-implant during the same procedure, complications and success rates.

With reference to facilities, equipment and personnel, the next data were researched and analyzed: location (operating room, cath/electrophysiology lab or hybrid lab), primary operator (surgeon, cardiologist or cardiothoracic surgeon standby), anaesthesia support (general or IV moderate sedation) and techniques and tools. Supplemental information or comments by investigators were provided by reporters in a text format.

Definitions published in the guidance documents by HRS (2009), EHRA (2012) and EHRA (2018) were used to define procedural approaches, techniques and outcomes. ${ }^{1-3}$

Data will be presented as a descriptive and statistical analysis. Categorical variables will be reported as counts and percentages. Study investigators had full access to all study data and approved all results provided in this manuscript.

\section{RESULTS}

Three hundred and twenty-five patients (average age of 59 years, $71 \%$ male) and 621 targeted leads (atrial: $38 \% ; \mathrm{n}=233$; ventricle $59 \% ; \mathrm{n}=367$; coronary sinus; $3 \% ; \mathrm{n}=21$ ) for TLE were obtained. The mean dwell time of the targeted leads averaged 105.9 months. Sixty-one percent of the targeted leads were pacemaker leads, $28 \%$ implantable cardioverter defibrillator leads and $11 \%$ cardiac resynchronization therapy Devices (CRTD). The mean number of leads extracted per device was 1.9.

The commonest indication for TLE was infection informed in $68 \%(222 / 325)$ of patients. Pathogens were identified in only $32 \%$ of cases. Bacterial culture data showed that staphylococcal infection was the most frequent $(71 \%)$.

Leads removal for non-infective indications (32\%) included lead dysfunction, abandoned lead dysfunction or other reasons (venous stenosis, access to magnetic resonance imaging, cardiac failure and arrhythmia). Demographic data including details on patients, leads and indications for removal are reported in Table 1.

Most procedures were performed by vascular or cardiovascular surgeons $(81 \%)$ working in the majority of cases in standard operating theatre $(79 \%)$. The remainder was performed by cardiologists or electrophysiologists, generally working in an electrophysiology laboratory (21\%). Procedures performed by a cardiologist or electrophysiology with cardiac surgical stand-by were reported in $65 \%$ of cases. In the majority of TLE interventions, general anaesthesia $(92 \% ; n=299)$ was preferred.

Most lead extractions were performed using a percutaneous approach (98\%). The majority began via identical route of lead implantation. Superior approach (subclavian/jugular/cephalic) was performed in 315 patients. Only in three cases, combination approaches (superior-femoral or inferior access) with additional snares or baskets were required. Simple traction without the use of specified tools (other than a standard stylet) was sufficient for removing $25 \%$ (158/621) of leads with a median dwell time of 33.3 months. 
For leads that could not be removed using simple traction $(75 \%$; $=463)$, a multistep approach was performed. Locking stylet was generally used in these steps. Additional equipment preferred by operators were quite variable from dilator sheaths, snares, baskets or mechanical rotational dilator sheaths (Evolution and Evolution RL, Cook Medical, USA) and most of them used in combination with others. No laser extractions were performed.

A small minority of leads ( 7 patients= 16 leads) were extracted by a simultaneous "hybrid approach" using a minithoracotomy/sternotomy (three patients with active endocarditis) including extracorporeal circulation and perfusionist.

Re-implant devices (leads + generator) during the same procedure was reported in $57 \%(185 / 325)$ of cases (permanent device: $65 \%=120 / 185$ ).

Complications were categorized in accordance with current 2018 EHRA recommendations. ${ }^{1}$ Overall complications rate were $4 \%$. The investigators reported only one major complication (outcome related to the procedure involving disability, life threatening or death) in a patient who suffered a temporary ventricular fibrillation and sudden cardiac arrest with immediate cardiopulmonary resuscitation and recovery at 24 hours. No procedural mortality occurred in our cohort study.

Minor complications (outcome which did not limit patient 's function, life threatening or death) were observed in 12 patients $(3.6 \%)$. Infection was the indication for lead extraction in more than half of these patients. Two patients experienced local haematoma related to lead extraction procedure due to extensive fibrosis. Vascular repair was informed in one patient with lead disruption during extraction and a femoral approach using a snare was required. Only one patient experienced an haemothorax which did not require intervention and an epicardial pacing was re-implanted at $24 \mathrm{hs}$. Details on incidence and types of complications are summarized in Table 2 .

Complete procedural success rates (removal of all targeted leads and material) were achieved for $96.2 \%$ $(598 / 621)$ of leads. Procedural failure rates (inability to achieve a complete procedural) were $3.7 \%$. Twentythree leads were incompletely extracted and more than half of them were related to infection. The mean dwell time was 134 months. Extensive fibrosis, presence of calcification and venous stenosis or occlusion were commented by investigators. At hospital discharge, lead fragments did not result in any undesired outcomes. No permanent disabling complications or procedure-related death were reported

\section{DISCUSSION}

The number of cardiac implantable electronic device (CIED) implantations has increased over recent years as a result of population growth, life expectancy, improving recognition of clinical needs, wider indications, and better access to healthcare. Lead extractions (LE) have also been increasing not only as a consequence of this growth, but also because of increasing rates of infections, lead failures, awareness of indications for lead management, and development of extraction tools. ${ }^{1 .}$ Since time ago, lead removal has been considered a complex open surgical procedure performed as a last resort and associated with significant mortality. ${ }^{2,3}$ Percutaneous approach compared with median sternotomy is an endovascular intervention more amenable for patients with several comorbidities.

Numerous reports of single and multi-centre TLE experiences have formed the basis of guidelines for the practice of LE. ${ }^{4-13}$

In Argentina, the first TLE was performed in 1993 at the Pirovano Hospital. ${ }^{14}$. Despite long experience, ${ }^{15}$ Argentina has not had a global and institutional clinical investigation on real-world patients. This report describes for the first time the indications, role of the operators, procedures, different operating environments and safety and effectiveness of mechanical extraction including tools and techniques. More than 600 procedures were performed over a mean of two years which represent the reflection of our current practice. The results as detailed above provide an useful resource for research and improvements in care.

Patients enrolled in RENEDI had similar demographics characteristics respect to other TLE studies including 
age and preponderance of gender. Lead characteristics (leads types and mean implant time) were also similar to previous publications. ${ }^{3,4,10,11}$ The most frequent indication for removal was infection but in contrast with other papers, we had a higher local compromise (isolated pocket infection, signs of inflammation or erosion) than systemic. ${ }^{5,7,10,11,13}$ All local manifestations were considered suspicious of infection although mechanical factors could also be related. According to consensus document, the whole of them were treated by complete removal. ${ }^{17,18}$

Despite clinical studies have shown that abandoning non-infective leads is generally safe ${ }^{19}$, our results in accordance with current literature show that removing rather than abandoning non-functional leads were also preferred. ${ }^{2,3,10}$

In contrast with other studies ${ }^{20,21}$, vascular and cardiovascular surgeons were usually the primary operator and operation theater was the room preferred to achieve these interventions. In almost $20 \%$ of cases, procedures were performed by interventional cardiologist as primary operator. It is relevant to emphasize that presence of stand-by was desired in $72 \%$ (236/325) of the total of TLE. As the guidelines recommend 1-3, we consider that the presence of stand-by on site should be highly considered since the potential for an unexpected cardiovascular complication always exists.

Regarding tools and techniques, simple traction (without the use of any additional equipment other than a standard stylet) was reported in $25 \%$ of TLE. It is known that this technique is usually effective for leads with a short dwell time ( $<1-2$ years). However, in our cohort study, the mean implant duration was longer than in other similar papers or guidelines recommendations. ${ }^{1,7}$

Our incidence of complications was low. Only one major complication was reported and no mortality occurred during our study. Other publications have also demonstrated a similar rate of complications and low risk of

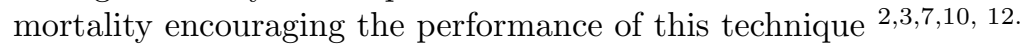

RENEDI showed a high complete procedural success rate in line with recent results of RELEASE, PROMET AND ELECTRA database analysis suggesting that TLE is a safe and efficacy procedure. ${ }^{5,7,10}$. Comparisons of TLE complications and success rate in current literature is informed in Table 3.

Although various issues may impact and influence on successful final outcomes, we consider that a key factor is the experience and training. In our registry all physicians were well-trained surgeons and cardiologists with a vast experience. As for all interventional procedure, an extensive and high quality learning curve is essential to become a competent operator in performing these techniques and minimize the risk of unnecessary and unexpected events. ${ }^{20,21}$

This registry is subject to the limitations inherent to observational studies. The participation in our study was based on a voluntary basis and no specific protocol or recommendations regarding techniques were made for TLE procedures as such bias in management strategy could have existed. Furthermore, follow-up was limited to only hospital discharge.

\section{CONCLUSIONS}

RENEDI is the first large prospective and observational registry designed in Argentina. This cohort study reflects our real world practice obtaining similar results to other worldwide experiences and following recent guidelines. Our data confirm in agreement with other papers that TLE is a safe and effective procedure associated with a low incidence of complications and high success rates when it is performed in well-trained hands. In Argentina, few specialists are dedicated to this practice developing a high quality training and remarkable experience in performing these interventions. We emphasize the necessity for extended training and sufficient prior experience to minimize risk of complications and obtain better outcomes.

\section{Acknowledgement}

The authors thank all patients who participated in this study, as well as all the study investigators and research personnel. The authors thank the following individuals Fraguas Hugo, MD; Blanco Rocio, MD; Salvo Gustavo, MD; Robi Marcelo, MD; Duval Javier, MD; Reyes Prieto Gabriela, MD; Talin Carlos, MD; 
Picolin Agustín, MD; Figueroa Jorge MD; Cronshey Andrés, MD; Zanuttini Antonella, MD; Deluso Daniel, MD; Pérez Salamanca MD; Perona Carlos MD and Cotti César MD for their contributions to the development of this manuscript.

\section{REFERENCES}

Bongiorni MG, Burri H, Deharo JC et al. 2018 EHRA expert consensus statement on lead extraction: recommendations on definitions, endpoints, research trial design, and data collection requirements for clinical scientific studies and registries: endorsed by APHRS/HRS/LAHRS. Europace. 2018 Jul 1;20(7):1217. doi: 10.1093/europace/euy050. Erratum in: Europace. 2018 Jul 1;20(7):1167. PMID: 29566158.

Wilkoff BL, Love CJ, Byrd CL et al. Transvenous lead extraction: Heart Rhythm Society expert consensus on facilities, training, indications, and patient management: this document was endorsed by the American Heart Association (AHA). Heart Rhythm 2009;6: 1085-104.

Kusumoto F, Wilkoff BL, Schoenfeld MH et al. 2017 HRS Expert Consensus Statement on CIED lead management and extraction. Heart Rhythm 2017;14: e503-51.

Deharo JC, Bongiorni MG, Rozkovec A et al. Pathways for training and accreditation for transvenous lead extraction: a European Heart Rhythm Association position paper. Europace 2012; 14:124-34.

Sharma S, Lee BK, Garg A et al. Performance and Outcomes of Transvenous Rotational Lead Extraction: Results from a Prospective, Monitored, International Clinical Study, Heart Rhythm O2 (2021), doi: https://doi.org/10.1016/j.hroo.2021.02.005.

Wazni O, Epstein LM, Carrillo RG, et al. Lead extraction in the contemporary setting: the LExICon study: an observational retrospective study of consecutive laser lead extractions. J Am Coll Cardiol Feb 9 2010; 55:579-586 '10.1016/j.jacc.2009.08.070:" 10.1016/j.jacc.2009.08.070.

Bongiorni MG, Kennergren C, Butter C, et al. The European Lead Extraction ConTRolled (ELECTRa) study: a European Heart Rhythm Association (EHRA) Registry of Transvenous Lead Extraction Outcomes. Eur Heart J Oct 21 2017; 38:2995-3005 '10.1093/eurheartj/ehx080:" 10.1093/eurheartj/ehx080.

Greenspon AJ, Patel JD, Lau E et al. Trends in permanent pacemaker implantation in the United States from 1993 to 2009: increasing complexity of patients and procedures. J Am Coll Cardiol 2012; 60:1540-1545.

Diemberger I, Mazzotti A, Giulia MB et al. From lead management to implanted patient management: systematic review and meta-analysis of the last 15 years of experience in lead extraction. Expert Rev Med Devices 2013; 10:551-573.

Starck CT, Gonzalez E, Al-Razzo O, et al. Results of the Patient-Related Outcomes of Mechanical lead Extraction Techniques (PROMET) study: a multicentre retrospective study on advanced mechanical lead extraction techniques. Europace Jul 1 2020; 22:1103- 1110 '10.1093/europace/euaa103:" 10.1093/europace/euaa103.

Mazzone P, Migliore F, Bertaglia E, et al. Safety and efficacy of the new bidirectional rotational Evolution(R) mechanical lead extraction sheath: results from a multicentre Italian registry. Europace May 1 2018;20:829834 '10.1093/europace/eux020:" 10.1093/europace/eux020.

Centella, T., Oliva, E., García-Andrade, I. et al. Extracción de electrodos de marcapasos y desfibrilador mediante técnicas percutáneas. Revista Española de Cardiología, 2007; 60(6), 607-615. doi:10.1157/13107117

Farooqi FM, Talsania S, Hamid S et al. Extraction of cardiac rhythm devices: indications, techniques and outcomes for the removal of pacemaker and defibrillator leads. Int J Clin Pract. 2010 Jul;64(8):1140-7. doi: 10.1111/j.1742-1241.2010.02338.x. PMID: 20642712.

Sandoe JA, Barlow G, Chambers JB et al. 2015 Guidelines for the diagnosis, prevention and management of implantable cardiac electronic device infection. Report of a joint Working Party project on behalf of the British Society for Antimicrobial Chemotherapy (BSAC, host organization), British Heart Rhythm Society 
(BHRS), British Cardiovascular Society (BCS), British Heart Valve Society (BHVS) and British Society for Echocardiography (BSE). J Antimicrob Chemother 70:325-359. doi:10.1093/jac/dku383.

Mazzetti H, Tentori C, Dussaut E et al. Técnica alternativa de extracción de catéteres endocavitarios atrapados. Rev Argent Cirug 1996;70: 61-3.

Mazzetti HA, Mascheroni O. Doce años de extracciones de catéteres endocavitarios de marcapasos y desfibriladores en la Argentina. Rev Argent Cardiol 2006; 74:117-122.

Sandoe JA, Barlow G, Chambers JB et al. 2015 Guidelines for the diagnosis, prevention and management of implantable cardiac electronic device infection. Report of a joint Working Party project on behalf of the British Society for Antimicrobial Chemotherapy (BSAC, host organization), British Heart Rhythm Society (BHRS), British Cardiovascular Society (BCS), British Heart Valve Society (BHVS) and British Society for Echocardiography (BSE). J Antimicrob Chemother 70:325-359. doi:10.1093/jac/dku383.

Bongiorni MG, Marinskis G, Lip GY et al. How European centres diagnose, treat, and prevent CIED infections: results of an European Heart Rhythm Association survey. Europace 2012; 14:1666-1669.

Glikson M, Suleiman M, Luria DM et al. Do abandoned leads pose risk to implantable cardioverterdefibrillator patients?Heart Rhythm 2009;6:65-8.

van Erven L, Morgan JM; Scientific Initiatives Committee (SIC). Attitude towards redundant leads and the practice of lead extractions: a European survey. Europace. 2010 Feb;12(2):275-6. doi: 10.1093/europace/eup443. PMID: 20089754.

Bongiorni MG, Blomstro"m-Lundqvist C, Kennergren C et al. Scientific Initiative Committee, European Heart Rhythm Association. Current practice in transvenous lead extraction: a European Heart Rhythm Association EP Network Survey. Europace 2012; 14:783-786. 
Table 1

\begin{tabular}{|c|c|c|}
\hline \multicolumn{3}{|c|}{ Demographic data } \\
\hline \multicolumn{3}{|c|}{ PATIENTS } \\
\hline Patient number & & 325 \\
\hline Age & \multicolumn{2}{|r|}{ average 59 years } \\
\hline \multicolumn{3}{|l|}{ Gender } \\
\hline & Male $(n=231)$ & $71 \%$ \\
\hline & Female $(n=94)$ & $29 \%$ \\
\hline \multicolumn{3}{|c|}{ LEADS } \\
\hline \multirow[t]{2}{*}{ Number of targeted leads } & & 621 \\
\hline & \multicolumn{2}{|c|}{$\begin{array}{l}61 \% \text { pacemaker leads } \\
28 \% \text { implantable cardioverter defibrillator leads } \\
11 \% \text { cardiac resynchronization therapy leads }\end{array}$} \\
\hline Implant duration & \multicolumn{2}{|r|}{ average 105.9 months } \\
\hline \multicolumn{3}{|l|}{ Localisation of leads } \\
\hline & Atrium $(n=233)$ & $38 \%$ \\
\hline & Ventricule $(n=367)$ & $59 \%$ \\
\hline & Coronary sinus $(n=21)$ & $3 \%$ \\
\hline Mean lead extracted per device & & 1.9 \\
\hline \multicolumn{3}{|c|}{ INDICATIONS FOR REMOVAL } \\
\hline Infection & & $68 \%(222 / 325)$ \\
\hline Local & $71 \%(158 / 222)$ & \\
\hline Local + systemic & $25 \%(55 / 222)$ & \\
\hline Systemic & $4 \%(9 / 222)$ & \\
\hline Lead dysfunction & & $26 \%(84 / 325)$ \\
\hline Abandoned lead dysfunction & & $3 \%(11 / 325)$ \\
\hline Other reasons & & $3 \%(8 / 325)$ \\
\hline
\end{tabular}


Table 2 - Incidence of complications

\begin{tabular}{|c|c|}
\hline $\begin{array}{c}\text { MAJOR COMPLICATIONS } \\
(\mathbf{0 . 3} \%=1 / 325)\end{array}$ & Cardiac arrest (1) \\
\hline \multirow{4}{*}{$\begin{array}{c}\text { MINOR COMPLICATIONS } \\
(3.6 \%=12 / 325)\end{array}$} & $\begin{array}{c}\text { Venous thrombosis (1) } \\
\text { Vascular repair at venous entry } \\
\text { site (2) }\end{array}$ \\
\cline { 2 - 2 } & $\begin{array}{c}\text { Bleeding requiring blood } \\
\text { transfusion (2) }\end{array}$ \\
\cline { 2 - 2 } & $\begin{array}{c}\text { Pulmonary embolism (1) } \\
\text { intervention (1) }\end{array}$ \\
\cline { 2 - 2 } & $\begin{array}{c}\text { Haematoma no requiring } \\
\text { evacuation (2) }\end{array}$ \\
\cline { 2 - 2 } & Arrytmhia (2) \\
\cline { 2 - 2 } & Unknown (1) \\
\cline { 2 - 2 } & \\
\hline
\end{tabular}




\begin{tabular}{c|c|c|c|c|c} 
& \multicolumn{5}{|c}{ Table 3 - Complications and success rate reported in literature } \\
& $\begin{array}{c}\text { MAJOR } \\
\text { COMPLICATIONS }\end{array}$ & $\begin{array}{c}\text { MINOR } \\
\text { COMPLICATIONS }\end{array}$ & $\begin{array}{c}\text { PROCEDURE } \\
\text { RELATED-DEATH }\end{array}$ & $\begin{array}{c}\text { COMPLETE } \\
\text { PROCEDURAL } \\
\text { SUCCESS }\end{array}$ & $\begin{array}{c}\text { CLINICAL } \\
\text { PROCEDURAL } \\
\text { SUCCESS }\end{array}$ \\
\hline RELEASE 20215 & $2.6 \%$ & $18 \%$ & 0 & $96.3 \%$ & $98.7 \%$ \\
\hline PROMET 202010 & $1 \%$ & $3.1 \%$ & $0.18 \%$ & $96.5 \%$ & $97 \%$ \\
\hline ELECTRA 2017 & $1.7 \%$ & $5 \%$ & $0.5 \%$ & $95.7 \%$ & $96.7 \%$ \\
\hline LEXICON 2010 & $4 \%$ & $1.8 \%$ & $1.86 \%$ & $96.5 \%$ & $97.7 \%$ \\
\hline CENTELLA ET AL 2007 12 & $2.5 \%$ & $2.1 \%$ & $0.5 \%$ & $96.8 \%$, & $99.04 \%$
\end{tabular}

